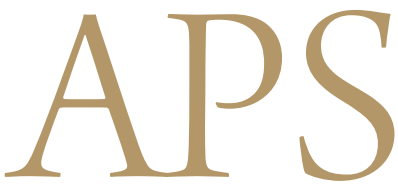

Archives of Plastic Surgery

\title{
Anatomic basis for flap thinning
}

\author{
Seong Oh Park ${ }^{1}$, Hak Chang ${ }^{2}$, Nobuaki Imanishi ${ }^{3}$ \\ ${ }^{I}$ Department of Plastic and Reconstructive Surgery, Hanyang University Medical Center, Hanyang University College of Medicine, Seoul; \\ ${ }^{2}$ Department of Plastic and Reconstructive Surgery, Seoul National University College of Medicine, Seoul, Korea; ${ }^{3}$ Department of Anatomy, \\ Keio University College of Medicine, Tokyo, Japan
}

Flap thinning is a procedure for making a thick flap thinner. This procedure does more than simply fill in the defected area, and it is better for reconstructing the area both functionally and aesthetically. However, because flap thinning is a rather blind procedure, it may have harmful effects on flap vascularity. Therefore, the vasculature of a flap must be understood before performing flap thinning. This paper analyzes the basic anatomy underlying flap thinning based on the previous anatomic study that categorized flaps into 6 types by their vascular structures. This paper also reviews specific studies of frequently practiced flap procedures (deep inferior epigastric artery perforator flap, thoracodorsal artery perforator flap, and anterolateral thigh flap) and presents important precautions for flap thinning procedures. Finally, this paper briefly examines the axiality of the subdermal plexus, which needs to be taken into account when performing flap thinning.

Keywords Flap thinning / Flap anatomy / Thin flap

Received: 14 Sep $2017 \bullet$ Revised: 14 Oct 2017 • Accepted: 7 Jan 2018

pISSN: 2234-6163 • elSSN: 2234-6171 • https://doi.org/10.5999/aps.2017.01543 • Arch Plast Surg 2018;45:298-303
Correspondence: Hak Chang

Department of Plastic and

Reconstructive Surgery, Research

Institute of Plastic and Reconstructive

Surgery, Ischemic/Hypoxic Disease Institute, Seoul National University College of Medicine, 101 Daehak-ro, Jongno-gu, Seoul 03080, Korea

Tel: +82-2-2072-3086

Fax: +82-2-747-5130

E-mail: hchang@snu.ac.kr

\section{INTRODUCTION}

With the development of reconstructive microsurgery methods, many attempts have been made to achieve better aesthetic and functional results that go beyond filling in the area of the defect. The face, dorsal side of the hand, and head and neck typically require a thin flap for reconstruction. If an elevated flap from the donor area is thick, a flap thinning procedure can be used to make the flap thinner.

While flap thinning can bring better reconstructive results, it can also cause problems in the blood flow of the flap; therefore, it is critical to have an understanding of the anatomical structure of blood vessels prior to conducting the procedure. There are two major factors to consider regarding the anatomical structure of blood vessels: first, the depth and direction of the blood vessel; and second, the axiality of the blood vessel. Combining this information, it can be seen that ultimately it is necessary to have a 3-dimensional understanding of vascular structure.

\section{FLAP THINNING METHOD}

In order to elevate a thin flap, the flap needs to be elevated in a thin form from the very beginning of the procedure, or the elevated flap needs to go through a thinning process by removing the fat located in the superficial level rather than in the deep fascial level (Fig. 1). Theoretically, a flap with the complete and ideal thickness can be made through skeletalization of just the vessel. However, this is difficult to do in practice and there is also a high risk of damaging the vessel during this process. Flap thinning is, strictly speaking, a rather blind procedure and it may harm the vascularity of the flap [1]. Studies have reported cases of successful flap thinning through microdissection under mi- 


\section{Fig. 1. Example of flap thinning}

(A) Fasciocutaneous flap prior to flap thinning. (B) Deep adipofascial tissue after thinning. The left side shows how defatting was performed while maintaining the vascularity of the flap, whereas the right side shows damaged flap vascularity due to defatting. (C) Superficial adipofascial tissue after thinning. The left side shows how defatting was performed while maintaining the vascularity of the flap, whereas the right side shows damaged flap vascularity due to defatting. SAL, superficial adipofascial layer; DAL, deep adipofascial layer.
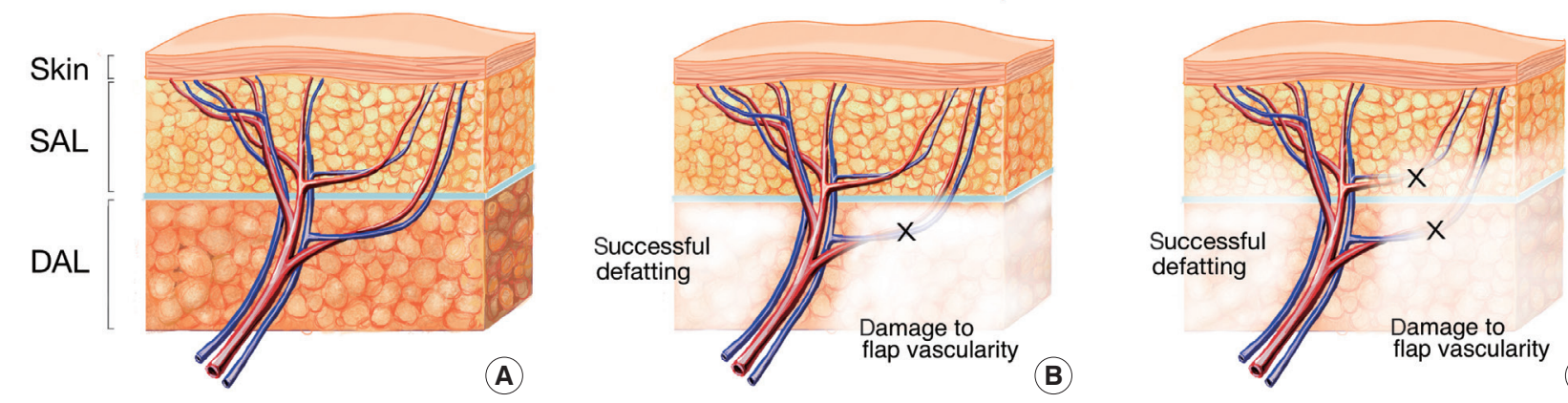

croscopic vision [1]; however, even microdissection can lead to negative results when performed without an understanding of the overall blood vessel structure.

Fig. 1 demonstrates how the structure of the blood vessel can contribute to successful defatting or have negative effects on the vascularity of the flap. Consequently, the key to safe and successful flap thinning is an understanding of the basic vasculature of the flap that is to be used before conducting the procedure.

\section{RESEARCH INTO THE ANATOMICAL STRUCTURE OF BLOOD VESSELS}

The anatomical study of flaps has investigated various clinical applications of flaps, leading naturally to research on flap thinning. Most of the research has tended to be specific to each flap [2-8]. The study published by Nakajima et al. [9] in 1998 may have been conducted in the past, without the benefit of the latest techniques, but it nonetheless presents a valuable and detailed 3-dimensional analysis and classification of the arteries of the dermis and subcutaneous adipofascial layer of the entire body. Based on that study, this paper will present an anatomical approach to flap thinning.

Their study describes in detail the course, branch formation, and axiality of blood vessels in the superficial layer of the deep fascia. Arteries and flaps were categorized into 6 types based on these descriptions. Fig. 2 is a flow chart of each category of blood vessel. In the image of the blood vessels, red indicates vessels in the deep adipofascial layer (DAL). Yellow corresponds to blood vessels in the superficial adipofascial layer (SAL), and blue depicts the blood vessels in the dermis. First of all, the major portion (main trunk and branches) is divided by whether it is composed of red or non-red. Then, if the axiality is definite and follows the red portion in 1 or 2 directions, it is categorized as strong. If several red branches branch in the same direction, they are categorized as moderate, and if the branching is variegated and axiality is indeterminable, they are categorized as none. A detailed description and example of each category are presented in Table 1.

This categorization of the types of blood vessels is related to the inner vasculature of the flap; therefore, an assessment using these categories can serve as a basis for examining the characteristics of each flap type and method of flap thinning. It is, of course, necessary to have a full prior understanding of the research conducted by Nakajima et al. [9], as summarized in Fig. 3 and Table 1.

\section{Type I-based flap}

If the main nutrient artery can be preserved, it is possible to make a thin flap with the subcutaneous adipofascial tissue removed. It is possible to harvest a free adipofascial flap. An example is the groin adipofascial flap. If the adipofascial layer is used as the flap pedicle, a flap with a skin island can be made, as in the adipofascial pedicled flap.

\section{Type II-based flap}

The concomitant artery of a cutaneous nerve or vein becomes the main source of a flap. If the adipofascial pedicle near the cutaneous nerve and/or vein can be preserved, a thin flap can be elevated. This is in accord with the concept of the veno-accompanying artery adipofascial flap, neuro-accompanying artery adipofascial flap, and veno-neuro-accompanying artery adipofascial flap. The most obvious example of this type is the sural flap [10-12]. 


\section{Fig. 2. Six types of arteries}

Categorization of 6 types of arteries based on a 3-dimensional analysis. Reproduced from Nakajima et al. Plast Reconstr Surg 1998;102:748-60 [9].

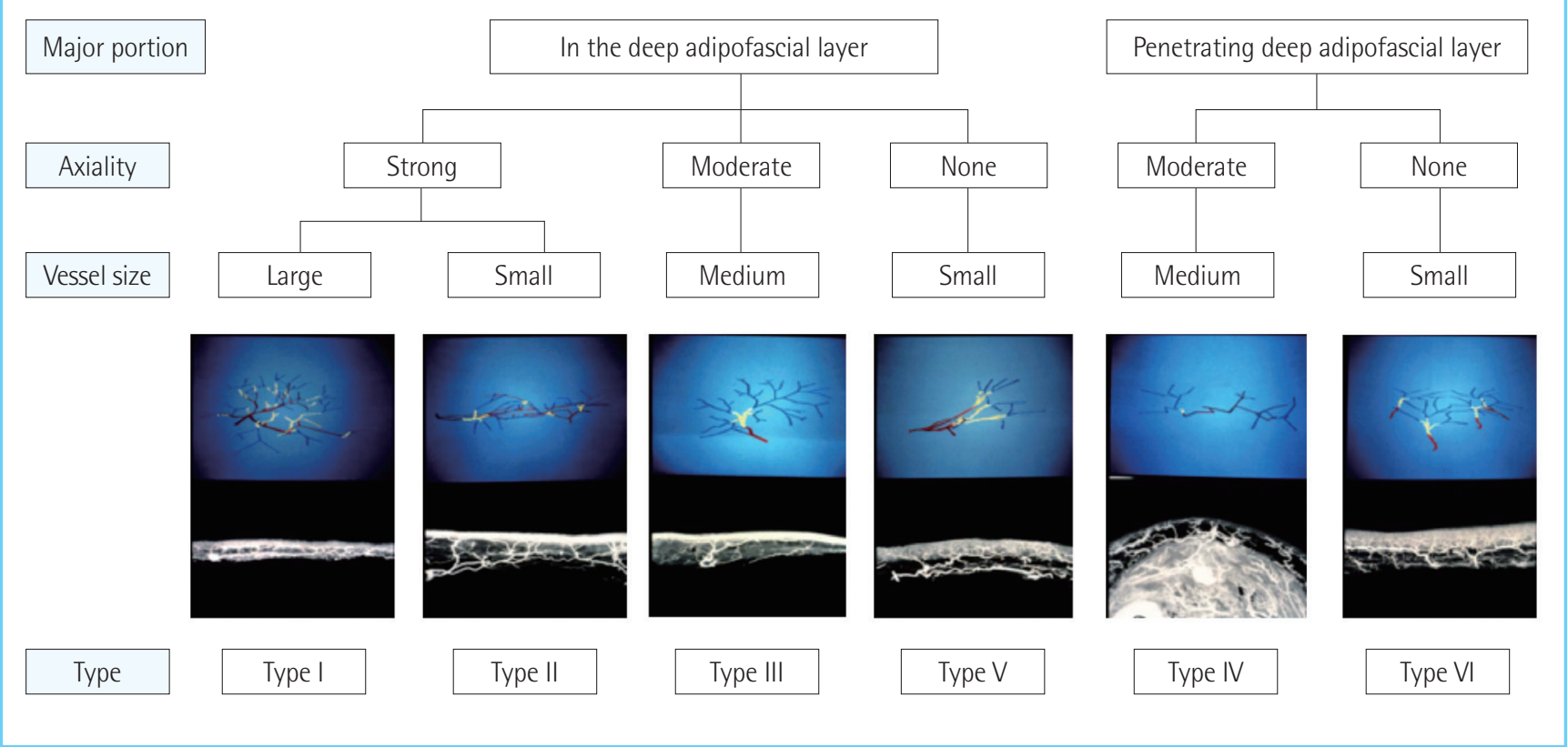

Table 1. Details of the types of vasculature classified [9]

\begin{tabular}{|c|c|c|}
\hline & Definition & Examples \\
\hline Type I & $\begin{array}{l}\text { Large vessel that runs and arborizes in the deep adipofascial layer. } \\
\text { Definite axiality; this axiality continues to the subdermal plexus. }\end{array}$ & $\begin{array}{l}\text { Peripheral portion of the direct cutaneous artery, superficial } \\
\text { circumflex scapular artery, lateral thoracic artery, superficial } \\
\text { epigastric artery, perforators of the internal thoracic artery. }\end{array}$ \\
\hline Type ॥ & $\begin{array}{l}\text { Thin vessel }(<1 \mathrm{~mm}) \text { that runs with the cutaneous nerve or cutaneous vein on the } \\
\text { deep adipofascial layer. } \\
\text { Continues into the direct septocutaneous artery or often forms chain-links with type III } \\
\text { or type IV arteries. }\end{array}$ & $\begin{array}{l}\text { Sural artery, the descending branch of the inferior gluteal artery, } \\
\text { the antecubital artery accompanying the cutaneous nerve; the } \\
\text { long and short saphenous veins and cephalic and basilic veins } \\
\text { are also accompanied by arteries of this type. }\end{array}$ \\
\hline Type III & $\begin{array}{l}\text { Mid-size vessel (1.0-1.5 mm) that has a long course in the deep adipofascial layer and } \\
\text { branches; is oblique in 3-dimensional images. } \\
\text { Peripheral continuation of the direct cutaneous branch or perforating cutaneous branch } \\
\text { of a muscular vessel. }\end{array}$ & $\begin{array}{l}\text { Superficial cervical artery, dorsal and lateral perforating artery of } \\
\text { the posterior intercostal artery, lumbar artery, perforating artery } \\
\text { of the profunda femoris artery, lateral femoral circumflex artery. }\end{array}$ \\
\hline Type IV & $\begin{array}{l}\text { Mid-size vessel }(1.0-1.5 \mathrm{~mm}) \text { that has a vertical stem, and rarely branches in the deep } \\
\text { adipofascial layer. } \\
\text { Considerable axiality, mainly in the subdermal plexus. } \\
\text { Peripheral continuation of the perforators exemplified by type III. } \\
\text { Type IV has a different branching point from type III. } \\
\text { Type III branches in the deep adipofascial layer, while type IV branches in the superficial } \\
\text { adipofascial layer. }\end{array}$ & $\begin{array}{l}\text { Thoracodorsal artery, thoracoacromial artery, deep inferior } \\
\text { epigastric artery. }\end{array}$ \\
\hline Type V & $\begin{array}{l}\text { Small septocutaneous perforators }(<1 \mathrm{~mm}) \text { observed in the extremities. } \\
\text { Branches in the deep adipofascial layer with almost no axiality and flows vertically to } \\
\text { the subdermal plexus. }\end{array}$ & Major arteries of the extremities (radial artery). \\
\hline Type VI & $\begin{array}{l}\text { Small musculocutaneous perforators }(<1 \mathrm{~mm}) \text {, with almost no branching. } \\
\text { Has low axiality, similar to type V, but branches in a more superficial layer. } \\
\text { Similar to type IV, but the type IV vessel diameter is larger and the axiality is greater. }\end{array}$ & Perforators of the latissimus dorsi, gluteus maximus muscles. \\
\hline
\end{tabular}

\section{Type III-based flap}

The vessel starts at the DAL and connects to either the direct cutaneous branch or the perforating cutaneous branch of muscular arteries. Therefore, if the blood vessel is preserved with consideration of the axiality of the vessel in the DAL, thinning of the peripheral tissues is possible.

\section{Type IV-based flap}

With the direct cutaneous branch of a muscular vessel as the base, branching starts at the SAL, meaning that it is possible to 


\section{Fig. 3. Six types of 3 -dimensional flap structure}

Schematic illustration of the 6 types of 3-dimensional flap structure based on arterial structure. SAL, superficial adipofascial layer; DAL, deep adipofascial layer. Reproduced from Nakajima et al. Plast Reconstr Surg 1998;102:748-60 [9].

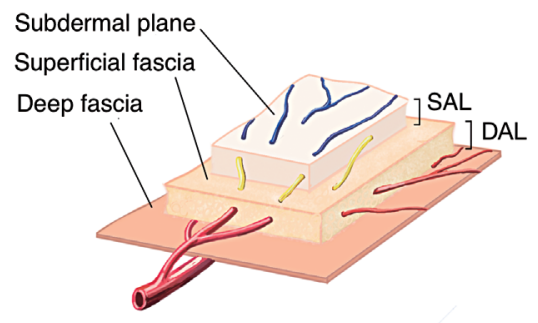

Type I

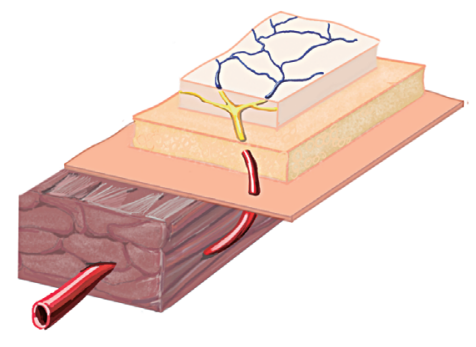

Type IV

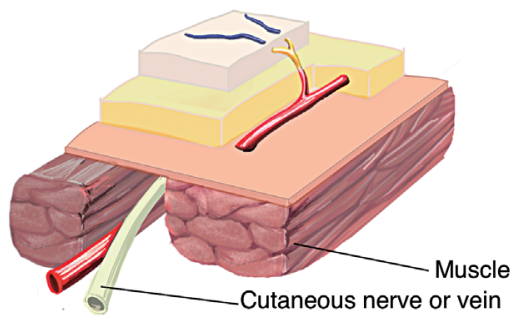

Type II

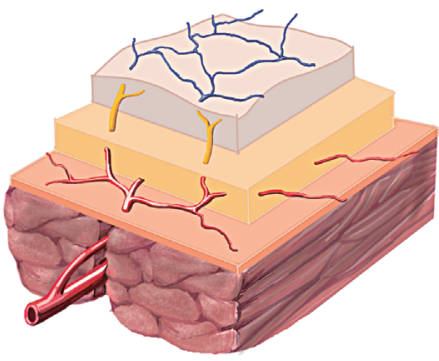

Type V

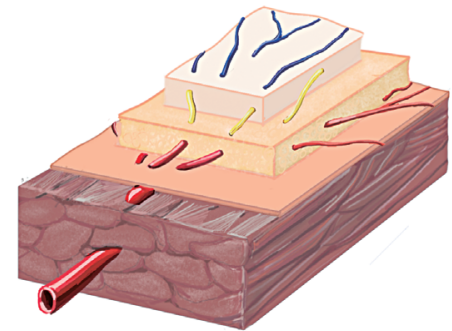

Type III

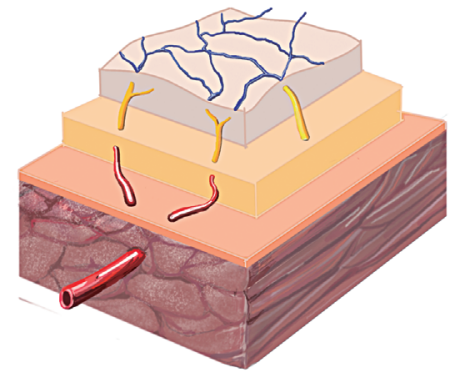

Type VI elevate it as a thin flap. Example: thin extended latissimus dorsi flap, thin abdominal flap.

\section{Type $\mathrm{V}$ - and type VI-based flaps}

These flaps were considered random perforator flaps in the past; however more recent research suggests that they have minimal but discernible axiality in the subdermal plexus, affected by the adjacent perforators. Theoretically, septocutaneous and musculocutaneous flaps are possible. Representative examples would include the thin forearm and thin latissimus dorsi flaps.

\section{Summary}

Flap thinning is made possible when the detailed anatomy of each flap is taken into account. The information described in the previous section may exceed the range of information commonly considered for flap thinning. Type I- and type II-based adipofascial flaps are typical examples of this. When performing flap thinning, fat located in a deeper layer than the superficial fascia is removed. The blood vessels located between fat tissues, therefore, can also be removed during this process. The blood vessel marked in red in Fig. 2 is located in a deeper layer than the super- ficial fascia and can be removed when performing flap thinning. The vessel marked in yellow is located at the SAL and the vessel marked in blue indicates blood vessels in the skin. As this is a type I example, the vessels progress in an axial dissection and arborize in the DAL, and there is a risk of removing or damaging the vessels while removing the fat tissues. This can lead to an adverse effect on flap vascularity. In contrast, in cases of type IV or type VI vasculature, the vessels most likely do not branch at the DAL. When they branch at the SAL, the major blood vessels that supply blood to the skin flap are at a low risk of damage even when the fat layer located in the DAL is removed. Therefore, it is safe to perform flap thinning on blood vessels and flaps in the categories of type IV and type VI proposed by Nakajima et al. [9].

\section{BLOOD VESSEL DISTRIBUTION BY TYPE}

The previous section presented information on each blood vessel type. The information that follows focuses on the distribution of blood vessels and their patterns throughout the entire body in order to determine areas suitable for flap thinning when 


\section{Fig. 4. Three kinds of subdermal vessels}

Angiography using lead oxide-gelatin mixture in fresh cadaver ( $\mathrm{x}$, a full-scale). (A) Vessels showing an elliptical skin territory arranged in a spoke-like fashion. (B) Vessels showing an elliptical skin territory arranged parallel. (C) Vessels showing a small and circular skin territory.
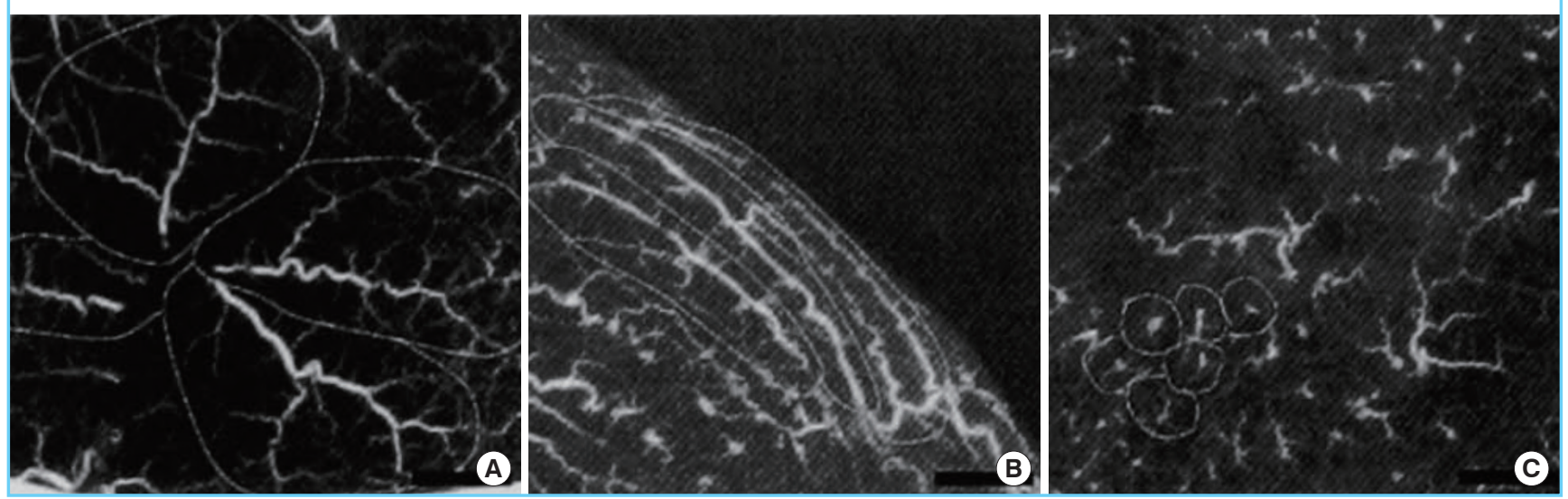

elevating flaps in practice, as well as areas to avoid for flap thinning. The summary of the vasculature above provides examples of the distribution of each blood vessel type; however, this section will briefly introduce the overall pattern of distribution [9]. The distribution can be largely divided into the torso and the extremities.

\section{Torso}

First of all, type I vessels are distributed in the major joint areas, such as the axilla and groin. These vessels start at and spread from the center of the joints. Type I vessels progress in the peripheral direction and interconnect with type III and type IV vessels. Therefore, type III and IV vessels are located near the axilla and groin, enclosing type I areas. Vessels located in other torso areas with large and flat muscles (latissimus dorsi, gluteus maximus and trapezius) are mostly type IV.

\section{Extremities}

Type V vessels are mostly present in the extremities. Type IV vessels are often found in areas with relatively large muscles (gastrocnemius), and type VI vessels are predominantly found on the palms and soles. Type II vessels are distributed following the origin and course of the cutaneous nerve and cutaneous vein.

\section{APPLICATION TO COMMONLY USED FLAPS}

Flaps with type IV and VI vasculature are ideal for flap thinning. They are as follows: (1) type IV: thoracodorsal artery, thoracoacromial artery, and deep inferior epigastric artery; (2) type VI: perforators of the latissimus dorsi and gluteus maximus muscles.

In the clinical and anatomical study of deep inferior epigastric artery perforator flaps performed by Rozen et al. [7], it was discovered that the perforator branches at a more superficial layer than the Scarpa fascia. This finding demonstrates that flap thinning at a deeper layer than the Scarpa fascia can be possible without damaging the blood flow of the flap. Furthermore, a study of thoracodorsal artery perforator flaps conducted by Schaverien et al. [4] found that flap thinning between the DAL and SAL did not affect the blood flow of the flap. That study discovered that there are two forms of blood vessels coming from the perforator: the first type rarely showed a horizontal course in the DAL, while the second type showed a horizontal course in the DAL, but the longest length of the horizontal course was $4.1 \mathrm{~cm}$, indicating that safe flap thinning can be conducted if $5 \mathrm{~cm}$ of the periphery of the perforator is preserved.

However, the lateral circumflex femoral artery, a pedicle of the anterolateral thigh (ALT) flap that is the most widely discussed vessel for flap thinning, is categorized as type III according to Nakajima et al. [9]. This artery runs for a long distance and arborizes in the DAL. Schaverien et al. [5] reported an anatomical study of the ALT flap, which confirmed that the suprafascial plexus is located and runs in the deep fascia layer and is connected to the subdermal plexus. Furthermore, several stages of thinning were conducted with an investigation of the corresponding vascular territory, and it was found that the more thinning was performed, the less vascular territory was present. The suprafascial plexus and the subdermal plexus are organically connected with what the authors call the recurrent vessel. If the suprafascial plexus is damaged, the connection will discontinue, and therefore the blood flow to the subdermal plexus will be weakened, which in turn weakens blood flow to the skin. 
However, studies have reported successful thinning of the ALT flap. Interestingly, these reports come from Japan and other Asian countries [2,13], while the success rate of thinning in people from the Western hemisphere is low [3]. Since the study of Schaverien et al. [4,5] was conducted among Westerners, it is necessary to investigate whether there are racial differences in this anatomical structure. Although ALT flap is not favorable for flap thinning theoretically, successful thinning of ALT flap in Japan and Asian group implies flap thinning can be possible in the flap of which vasculature is arborizing in SAL such as type III).

\section{FURTHER CONSIIDERATIONS}

Flap thinning inevitably damages vessels in the DAL. It is, therefore, necessary to consider the axiality of the subdermal plexus in order to preserve the blood flow of the flap and to elevate an appropriately sized flap. Type IV and VI vessels, in the classification developed by Nakajima et al., are the categories that have axiality. Type IV, especially, shows definite axiality, and was described in their study as having "considerable axiality mainly in the subdermal plexus."

Although previous studies have provided details on the facial subdermal plexus [14], a thorough study has yet to be conducted of the subdermal plexus in the torso. There are three different types of subdermal plexus in the facial area (Fig. 4). Although one may predict the tendency to some extent based on the direction of the source artery that starts before the perforator, even smaller areas, such as the facial area, showed differences throughout their area. It is necessary, therefore, to characterize the different types of the subdermal plexus, the presence of axiality, and its direction, if it exists, throughout the entire body.

\section{NOTES}

\section{Conflict of interest}

No potential conflict of interest relevant to this article was reported.

\section{ORCID}

Seong Oh Park https://orcid.org/0000-0001-8990-0635

Hak Chang https://orcid.org/0000-0002-1996-0680

\section{REFERENCES}

1. Kimura N, Satoh K, Hosaka Y. Microdissected thin perforator flaps: 46 cases. Plast Reconstr Surg 2003;112:1875-85.
2. Kimura N, Satoh K, Hasumi T, et al. Clinical application of the free thin anterolateral thigh flap in 31 consecutive patients. Plast Reconstr Surg 2001;108:1197-208.

3. Ross GL, Dunn R, Kirkpatrick J, et al. To thin or not to thin: the use of the anterolateral thigh flap in the reconstruction of intraoral defects. Br J Plast Surg 2003;56:409-13.

4. Schaverien M, Saint-Cyr M, Arbique G, et al. Three- and four-dimensional arterial and venous anatomies of the thoracodorsal artery perforator flap. Plast Reconstr Surg 2008; 121:1578-87.

5. Schaverien M, Saint-Cyr M, Arbique G, et al. Three-and four-dimensional computed tomographic angiography and venography of the anterolateral thigh perforator flap. Plast Reconstr Surg 2008; 121:1685-96.

6. Agostini T, Lazzeri D, Spinelli G. Anterolateral thigh flap thinning: techniques and complications. Ann Plast Surg 2014;72:246-52.

7. Rozen WM, Murray AC, Ashton MW, et al. The cutaneous course of deep inferior epigastric perforators: implications for flap thinning. J Plast Reconstr Aesthet Surg 2009;62: 986-90.

8. Sharabi SE, Hatef DA, Koshy JC, et al. Is primary thinning of the anterolateral thigh flap recommended? Ann Plast Surg 2010;65:555-9.

9. Nakajima H, Minabe T, Imanishi N. Three-dimensional analysis and classification of arteries in the skin and subcutaneous adipofascial tissue by computer graphics imaging. Plast Reconstr Surg 1998;102:748-60.

10. Imanishi N, Nakajima H, Fukuzumi S, et al. Venous drainage of the distally based lesser saphenous-sural veno-neuroadipofascial pedicled fasciocutaneous flap: a radiographic perfusion study. Plast Reconstr Surg 1999;103:494-8.

11. Nakajima H, Imanishi N, Fukuzumi S, et al. Accompanying arteries of the cutaneous veins and cutaneous nerves in the extremities: anatomical study and a concept of the venoadipofascial and/or neuroadipofascial pedicled fasciocutaneous flap. Plast Reconstr Surg 1998;102:779-91.

12. Nakajima H, Imanishi N, Fukuzumi S, et al. Accompanying arteries of the lesser saphenous vein and sural nerve: anatomic study and its clinical applications. Plast Reconstr Surg 1999; 103:104-20.

13. Kimura N, Satoh K. Consideration of a thin flap as an entity and clinical applications of the thin anterolateral thigh flap. Plast Reconstr Surg 1996;97:985-92.

14. Chang $\mathrm{H}$. Arterial anatomy of subdermal plexus of the face. Keio J Med 2001;50:31-4. 